\title{
The optic nerve and peripapillary vasculature in albinism
}

\author{
Julie Conley ${ }^{1}$, Alejandra Decanini Mancera ${ }^{1}$, Ann M. Holleschau ${ }^{1}$ and C. Gail Summers ${ }^{1,2 *}$ \\ ${ }^{1}$ Department of Ophthalmology \& Visual Neurosciences, University of Minnesota, Minneapolis, MN, USA \\ ${ }^{2}$ Department of Pediatrics, University of Minnesota, Minneapolis, MN, USA
}

\begin{abstract}
Albinism, an inherited disorder resulting in reduced ocular melanin, is usually associated with reduced best-corrected visual acuity, nystagmus, foveal hypoplasia, and iris transillumination. However, a spectrum of findings has been reported, with foveal hypoplasia, nystagmus, and misrouting of the retinostriate fibers having been purported to cause reduced visual acuity. The purpose of this case-controlled study is to describe the optic nerve anatomy and peripapillary retinal vasculature in albinism and to determine if there are changes related to visual acuity. We evaluated digital fundus photographs using computer analysis software in 34 patients with albinism and 51 controls. Our data indicate that the optic disc diameter and optic nerve area are significantly smaller in patients with albinism than controls ( $\mathrm{p}$ $<0.001 ; p=0.0008$, respectively). Significantly more patients with albinism also had a double ring sign, situs inversus, and a nasally-directed artery ( $\mathrm{p} \leq 0.0148$ ). There were no significant differences between groups for optic nerve color, vessel branching pattern, cilioretinal artery, or number of vessels crossing the optic nerve margin. Correlation of best-corrected visual acuity to disc diameter and optic nerve area was poor ( $\mathrm{r}=0.0542 \mathrm{r}=0.1527$, respectively). In this study, patients with albinism had mild optic nerve hypoplasia when compared to controls. Reduced best-corrected visual acuity is not explained by the optic nerve findings. Further studies are required to elucidate the causes of reduced best-corrected visual acuity in albinism.
\end{abstract}

\section{Introduction}

Albinism is an inherited disorder of melanin biosynthesis, resulting in absent or reduced melanin in the eyes, and often, in the skin and hair. Albinism occurs in approximately 1 in 17,000 in the United States $[1,2]$. Ocular manifestations typically include reduced visual acuity, nystagmus, iris transillumination, foveal hypoplasia, and misrouting of the retinostriate fibers, which refers to excessive decussation of some of the temporal nerve fibers to the contralateral central visual pathway [3-5]. A wide spectrum of visual acuity has been reported in albinism. The contribution of nystagmus, foveal hypoplasia, and misrouting to reduced acuity has not been quantified, and optic nerve changes may be another source of reduced visual acuity.

Optic nerve hypoplasia is typically characterized by a nonprogressive deficiency of nerve fiber layer and retinal ganglion cells, with best-corrected visual acuity ranging from normal to no light perception, depending on the extent of hypoplasia. Signs include a small neuroretinal rim, abnormal shape of nerve, optic nerve pallor, double ring sign, peripapillary abnormalities, abnormal vascular pattern, increased tortuosity, small or absent cup, fewer than normal vascular branching points, and disc diameter to disc macula ratio less than $0.3[6,7]$.

A previous study reported the subjective appearance of optic nerve hypoplasia in the majority of eyes in 12 persons with albinism [8]. Optic nerve studies in albinism have small sample size, lack specific parameters, have no normal comparative group, and have deficient quantitative evaluation of the optic nerve. The purpose of this study is to describe the anatomy of the optic nerve and the peripapillary retinal vasculature in patients with albinism, as compared to normal controls, and to correlate nerve head size with best-corrected visual acuity. The goal is to determine if a relationship between optic nerve structure and visual function exists in albinism.

\section{Methods}

This study was approved by the Institutional Review Board at the University of Minnesota, and was compliant with the Health Information Portability and Accountability Act. The fundus photos of 34 consecutive patients with ocular or oculocutaneous albinism that were analyzed for this study were obtained at enrollment in a prospective clinical trial [www.ClinicalTrials.gov (NCT01176435)]. Charts were reviewed to record best-corrected visual acuity and demographic information obtained at the time of enrollment. Bestcorrected visual acuity was measured using an electronic logMAR (log of minimum angle of resolution) chart [9]. In addition, optic nerve photographs from 51 control subjects without albinism or ocular disease were reviewed. All photographs were taken with the Zeiss FF4 fundus camera (Carl Zeiss, Jena, Germany) by one of two ophthalmic photographers. Images represented a $30^{\circ}$ field centered on the optic nerve. The camera has a telecentric optical design to adjust the measurements based on refractive error providing that the photograph is in good focus. Computer analysis software (Ophthavision, Sonomed Escalon, Stoneham, MA) was used to further analyze the photos and to make measurements, as described below.

Quality of the photograph was graded as excellent, good, or poor based on focus of image and whether the optic nerve was centered. It was graded excellent if both characteristics were achieved, good if only one, and poor if neither. We rejected any photograph that was graded as poor.

Correspondence to: C. Gail Summers, MD, Minnesota Lions Children's Eye Clinic, 701 25th Avenue South, \#300, Minneapolis, MN 55454, Tel: 612-6255484, Fax: 612-624-9337; E-mail: summe001@umn.edu

Key words: albinism, optic nerve, optic nerve hypoplasia, visual acuity

Received: February 10, 2016; Accepted: March 17, 2016; Published: March 21, 2016 
We did not use disc diameter to disc-macula ratio to grade optic nerve hypoplasia in this study, as designation of the intended "fovea" is difficult to determine in those with albinism who have foveal dysmorphology and an abnormal foveal avascular zone. The following optic nerve characteristics were systematically analyzed:

1. Color of the optic nerve, graded as normal, temporal pallor, or overall pallor.

2. Presence or absence of a double ring sign, defined by Brodsky [10], if there was a larger ring of increased or decreased pigmentation with a white or yellowish circumpapillary halo inside this ring (Figure 1).

3. Horizontal disc diameter, measured with a cursor to mark each side of the optic nerve, taking care to avoid including the scleral rim.

4. Optic nerve area, defined as total area inside the neuroretinal rim, excluding any double ring sign, and subtracting the area of the cup. The nerve tissue area and cup area were outlined with a cursor and then the area was calculated with the software.

In addition, the following characteristics of the papillary and peripapillary vasculature were systematically recorded.

1. Presence or absence of situs inversus, defined as central retinal vessels emerging nasally, instead of the temporally, from the optic nerve [11],

2. Branching of the superior and inferior arterial trunks before or after crossing the optic nerve margin,

3. Presence or absence of a cilioretinal artery, which appears at the optic disc margin, usually on the temporal side, as described in Duke-Elder [12],

4. Presence or absence of an artery extending in a nasal direction,

5. Number of vessels (arteries and veins) crossing the optic nerve rim,

6. Presence or absence of a vascular helix, defined as a vessel starting over one vessel and then going under or vice versa.

When differences in grading occurred, a third evaluator adjudicated the scoring.

\section{Results}

The 34 patients with albinism included 18 males and 16 females. Average age was 10 years (range: 3 to 44 years). Patients had

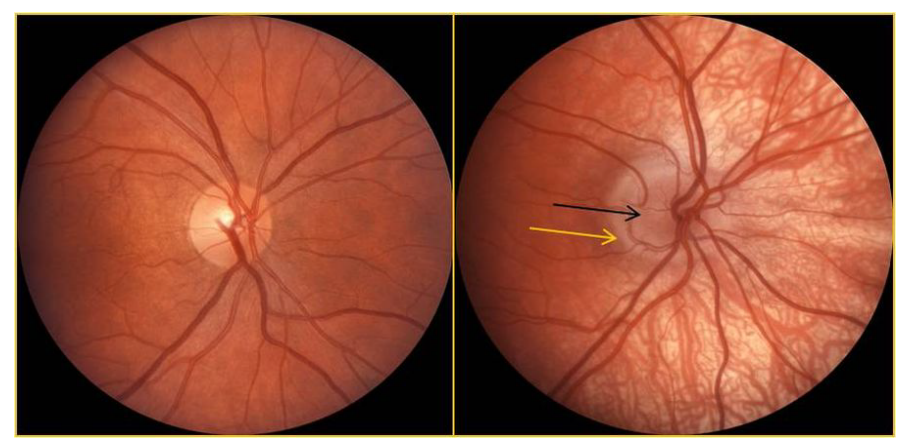

Figure 1. The left fundus photograph shows a normal optic nerve and vessels. The nerve in an individual with albinism is shown on the right; the dark arrow indicates nerve tissue and the lighter arrow indicates a peripapillary halo (double ring sign). oculocutaneous albinism (OCA) type 1A $(\mathrm{n}=8)$, OCA1B $(\mathrm{n}=14)$, OCA2 $(\mathrm{n}=10)$, Hermansky-Pudlak syndrome (HPS-1) $(\mathrm{n}=1)$ or ocular albinism type $1(\mathrm{n}=1)$. All but one (OCA2 based on history and phenotype) had at least one mutation in a gene known to cause albinism. Mean BCVA was 20/77 (range: 20/32 to 20/150). The 51 control subjects included 21 males and 30 females, with an average age of 30 years (range: 22 to 52 years). The majority of the photos were graded as excellent; 6 were graded as good due to the nerve not being perfectly centered, and 3 were graded as good due to slight defocus.

Best-corrected visual acuity of the right eye was similar to visual acuity of left eye $(\mathrm{p}<0.0001)$. Binocular best-corrected visual acuity was used, as 33/34 patients with albinism had nystagmus, which can degrade monocular visual acuity when the opposite eye is occluded or fogged due to increased nystagmus amplitude. Preliminary data showed that disc diameter and nerve tissue area was not significantly different between right and left eyes $(p=0.323, p=0.866$, respectively). Given this information, the right eye was chosen for data analysis.

Optic nerve: Significant differences between the group with albinism and the control group included a double ring sign, disc diameter, and nerve tissue area, as shown in the Table 1 . Three patients with albinism (9\%) and 8 controls (16\%) had mild temporal optic nerve pallor $(\mathrm{p}=0.5135)$. Neither disc diameter nor nerve tissue area correlated well with best-corrected visual acuity in the group with albinism ( $\mathrm{r}=0.0542, \mathrm{p}=0.7607 ; \mathrm{r}=0.1527 ; \mathrm{p}=0.3885$, respectively).

Vasculature: Findings that were significantly different between the two groups included situs inversus and a nasally directed artery $(\mathrm{p}<0.0001, \mathrm{p}=0.0148$, respectively). There were no significant differences in the branching pattern of the superior or inferior arterial trunks ( $\mathrm{p}=0.5774$ and 0.6905 , respectively). For the superior trunk in albinism, 27 (79\%) branched before crossing the optic nerve rim, 4 (12\%) branched at the rim, and $3(9 \%)$ branched beyond the rim, while $39(76 \%)$ control subjects branched before, $4(8 \%)$ at the rim, and 8 (16\%) beyond the rim. For the inferior artery in patients with albinism, 21 (62\%) branched before the rim, $9(26 \%)$ at the rim, and $4(12 \%)$ beyond; $36(71 \%)$ of control subjects branched before, $10(20 \%)$ at the rim, and 5 (10\%) beyond. There was also no difference in presence of cilioretinal artery between the two groups, with 11 (32\%) patients with albinism and 13 (25\%) controls having cilioretinal arteries ( $\mathrm{p}=0.6235)$. The mean number of vessels crossing the disc margin in patients with albinism was 10.65 and in controls was $9.922(\mathrm{p}=0.0531)$. A vascular helix was found in $11(32 \%)$ patients with albinism and $13(25 \%)$ controls $(\mathrm{p}=0.6235)$.

\section{Discussion}

Albinism is frequently associated with reduced visual acuity, but the etiology of decreased best-corrected visual acuity remains unknown. Many have described features associated with albinism that might affect visual function, including nystagmus, foveal hypoplasia, and retinostriate misrouting, but discussion of the optic nerve is usually

Table 1. Significant Differences between Subjects with Albinism and Controls.

\begin{tabular}{|l|c|c|c|}
\hline & Subjects with albinism & Controls & P-value \\
\hline $\begin{array}{l}\text { Double ring } \\
\text { (yes; partial; no) }\end{array}$ & $26 ; 7 ; 1$ & $1 ; 6 ; 44$ & $<0.0001$ \\
\hline Disc diameter & $1.604 \mathrm{~mm}$ & $1.754 \mathrm{~mm}$ & $<0.0001$ \\
\hline Nerve tissue area & $2.108 \mathrm{~mm}^{2}$ & $2.381 \mathrm{~mm}^{2}$ & 0.0008 \\
\hline Situs Inversus & 19 & 4 & $<0.001$ \\
\hline Nasally-directed Artery & 20 & 16 & 0.0148 \\
\hline
\end{tabular}


omitted. Of note, Spedick and Beauchamp [8] subjectively studied fundus photographs of 12 individuals with albinism, finding typical optic nerve hypoplasia in six eyes of four patients. In addition, ten eyes of six had qualitative features suggestive of optic nerve hypoplasia, including small nerves with abnormal shape, orientation, and vessel origination and peripapillary courses. Our study, using objective measurements of the right eye of 34 individuals with albinism, compared to a control group, showed that all but one had a peripapillary halo, and that the mean optic disc diameter was significantly smaller compared to the control group. The smaller disc diameter in patients with albinism could have possibly been accounted for by a smaller cup; however, the nerve tissue area was also significantly smaller, after accounting for smaller cupping. We believe that mild optic nerve hypoplasia occurs in most individuals with albinism. However, we failed to show that these findings were correlated with best-corrected visual acuity.

There are several potential causes of the variable reduction of visual acuity found in individuals with albinism. As all affected persons have some degree of foveal dysmorphology, this could explain reduced visual acuity from birth. Optical coherence tomography has further defined the arrest in foveal development [13-16]. However, it has recently been questioned whether foveal dysmorphology can completely account for the reduced visual acuity found in individuals with albinism [17-19]. The presence of granular melanin pigment in the retinal pigment epithelium has been associated with better vision in albinism, so presence or absence of macular pigment could also play a role [20-22]. Most patients with albinism have nystagmus, and frequently use an abnormal head posture to reduce the amplitude of their nystagmus. Despite the head posture, nystagmus persists and could correlate with vision loss; however, nystagmus could simply be a manifestation of abnormal structure of the visual pathway and not a primary determinant of reduced visual acuity. Others have investigated the cone photoreceptor mosaic in albinism with adaptive optics [15]. Some have used fMRI to evaluate the visual pathways in albinism and show reduced grey matter volume in the occipital lobes $[23,24]$ and abnormal retinotopographic mapping $[25,26]$.

We speculated that optic nerve hypoplasia, representing a reduced number of ganglion cells, as seen in Siamese cats [27] and humans with albinism [23], might further contribute to vision loss. However, this study did not find that reduction in neural tissue at the optic disk was associated the reduction in best-corrected visual acuity. This is unlikely due to the range of best-corrected visual acuity which is relatively broad and is more likely due to the mild nature of the hypoplasia. The mean optic nerve area for our patients $\left(2.108 \mathrm{~mm}^{2}\right)$ is greater than that found in patients who do not have albinism but do have optic nerve hypoplasia, in which median optic disc area was $1.34 \mathrm{~mm}^{2}$ for those with pituitary deficiency and $1.42 \mathrm{~mm}^{2}$ for those without pituitary deficiency [28]. We believe that optic nerve hypoplasia in albinism represents the mild end of the spectrum of optic nerve hypoplasia.

We also found significantly more patients with albinism with situs inversus and a nasally directed artery compared to controls, but any vascular changes related to vision loss are more likely to occur in the foveal area which is known to have an abnormal foveal avascular zone in albinism [19]. The amount of decussation was not studied in this report and may also contribute to vision loss. Lastly, structural abnormalities may be influenced by the mutations for albinism and modified by other genes affecting pigment and/or vision. Thus, the etiology of vision loss in albinism remains elusive and may be multifactorial.

In this study, the mean optic disc area for our controls was found to be $2.381 \mathrm{~mm}^{2}$, which is smaller than that reported in other studies. For example, a study of controls versus patients with periventricular leukomalacia found optic disc area to be $2.75 \mathrm{~mm}^{2}$ for control children ages 5-19 years [29]. However, the cupping of the disc is known to be increased in periventricular leukomalacia. Another study of 100 healthy children and adolescents revealed the median optic disc area to be $2.67 \mathrm{~mm}^{2}$, in subjects ages 3 to 19 years [30]. In another study the mean disc area was $2.49 \mathrm{~mm}^{2}$ in healthy and glaucomatous eyes [31]. These differences in optic disc area in control/normal subjects are likely related to different measurement techniques.

This study has certain strengths, including the relatively large number of patients with albinism, given the infrequency of the disorder. We used precise definitions of each parameter and fundus photographs were generally of excellent quality. The telecentric design of the fundus camera is optimized with excellent quality images, mitigating the need to use refraction in disc calculations. Limitations include use of only fundus photographs instead of also using data from optical coherence tomography to evaluate the optic nerve. The age of the controls was greater compared with the patients with albinism. However, Hellstrom et al. [30] found no change in the size of the disc, cup or rim with increasing age. In addition, we could not reliably use the ratio of disc diameter to distance of the optic nerve to the macula, used in other studies of optic nerve hypoplasia, due to the difficulty in defining the center of the foveal avascular zone in albinism. Lastly, this study was not masked, as patients with albinism have a distinctive fundus appearance, typically having absent melanin pigment in the retinal pigment epithelium, and when present, it is found primarily in the macula $[20,21]$.

The finding of mild optic nerve hypoplasia has relevance for counseling patients with albinism, as the size of the optic nerve does not predict visual acuity in these patients. It also provides a stepping stone for future research to further understand the etiology of decreased visual acuity and the structural and functional findings in the occipital cortex.

\section{Authorship and contributions}

All authors worked as a team to make substantial contributions to conception and design, or acquisition of data, or analysis and interpretation of data; drafting the article and revising it critically for important intellectual content; final approval of the version submitted for publication; agreement to act as guarantor of work (ensuring that questions related to any part of the work are appropriately investigated and resolved).

\section{Acknowledgements}

The authors would like to thank the subjects who participated in this study, in addition to ophthalmic photographers, Pat Harvey, CRA, OCT-C and Mark Cohen, Ophthalmic Imaging Specialist.

\section{Funding information}

Supported, in part, by an unrestricted grant from Research to Prevent Blindness, Inc., New York, NY, to the Department of Ophthalmology \& Visual Neurosciences at the University of Minnesota.

\section{Competing interest}

None of the authors decalre any competing interests.

\section{References}

1. Oetting WS, King RA(1999) Molecular basis of albinism: mutations and polymorphisms 
of pigmentation genes associated with albinism. Hum Mutat 13: 99-115. [Crossref]

2. Hutton SM, Spritz RA (2008) A comprehensive genetic study of autosomal recessive ocular albinism in Caucasian patients. Invest Ophthalmol Vis Sci 19: 868-872. [Crossref]

3. Hoffmann MB, Lorenz B, Morland AB, Schmidtborn LC (2005) Misrouting of the optic nerves in albinism: Estimation of the extent with visual evoked potentials. Invest Ophthalmol Vis Sci. 46: 3892-3898. [Crossref]

4. Merrill KS, Lavoie JD, King RA, Summers CG (2004) Positive angle kappa in albinism. J AAPOS 8: 237-239. [Crossref]

5. Brodsky MC, Fray KJ (2004) Positive angle kappa: a sign of albinism in patients with congenital nystagmus. Am J Ophthalmol 137: 625-629. [Crossref]

6. Hellström A, Wiklund LM, Svensson E (1999) The clinical and morphologic spectrum of optic nerve hypoplasia. J AAPOS 3: 212-220. [Crossref]

7. Taylor D (2007) Developmental abnormalities of the optic nerve and chiasm. Eye21: 1271-1284. [Crossref]

8. Spedick MJ, Beauchamp GR (1986) Retinal vascular and optic nerve abnormalities in albinism. J Pediatr Ophthalmol Strabismus 23: 58-63. [Crossref]

9. Moke PS, Turpin AH, Beck RW, Holmes JM, Repka MX, et al. (2001) Computerized method of visual acuity testing: Adaptation of the amblyopia treatment study visual acuity testing protocol. Am J Ophthalmol 132: 903-909. [Crossref]

10. Brodsky MC, Baker RS, Hamed LM (1996) Pediatric Neuro-Ophthalmology. New York: Springer-Verlag, 43-49.

11. Duke-Elder S (1958) System of Ophthalmology: Congenital Deformities. Volume III, Part 2. London: Henry Kimpton, 677.

12. Duke-Elder S (1958) System of Ophthalmology: The Anatomy of the Visual System. Volume II, London: Henry Kimpton, 345-346.

13. Seo JH, Yu YS, Kim JH, Choung HK, Heo JW, et al. (2007) Correlation of visual acuity with foveal hypoplasia grading by optical coherence tomography in albinism. Ophthalmology 114: 1547-1551. [Crossref]

14. Chong GT, Farsiu S, Freedman SF, Sarin N, Koreishi AF, et al. (2009)Abnormalfoveal morphology in ocular albinism imaged with spectral-domain optical coherence tomography. Arch Ophthalmol 127: 37-44. [Crossref]

15. McAllister JT, Dubis AM, Tait DM, Ostler S, Rha J, et al. (2010) Arrested development: high-resolution imaging of foveal morphology in albinism. Vision Res 50: 810817. [Crossref]

16. Thomas MG, Kumar A, Mohammad S, Proudlock FA, Engle EC, et al. (2011) Structura grading of foveal hypoplasia using spectral-domain optical coherence tomography a predictor of visual acuity? Ophthalmology 118: 1653-1660. [Crossref]
17. Marmor MF, Choi SS, Zawadzki RJ, Werner JS (2008) Visual insignificance of the foveal pit: reassessment of foveal hypoplasia as fovea plana. Arch Ophthalmol 126 907-913. [Crossref]

18. Mohammad S, Gottlob I, Kumar A, Thomas M, Degg C, et al. (2011) The functiona significance of foveal abnormalities in albinism measured using spectral-domain optical coherence tomography. Ophthalmology 118: 1645-1652. [Crossref]

19. Provis JM, Dubis AM, Maddess T, Carroll J (2013) Adaptation of the central retina for high acuity vision: cones, the fovea and the avascular zone. Prog Retin Eye Res35: 63-81. [Crossref]

20. Summers CG (1996) Vision in albinism. Trans Am OphthalmolSoc 94: 1095 1155. [Crossref]

21. Lee KA, King RA, Summers CG (2001) Stereopsis in patients with albinism: clinical correlates. JAAPOS5: 98-104. [Crossref]

22. Harvey PS, King RA, Summers CG (2006) Spectrum of foveal development in albinism detected with optical coherence tomography. J AAPOS 10: 237-242. [Crossref]

23. vondem Hagen EA, Houston GC, Hoffmann MB, Jeffery G, Morland AB (2005) Retinal abnormalities in human albinism translate into a reduction of grey matter in the occipital cortex. Eur J Neurosci 22: 2475-2480.[Crossref]

24. vondem Hagen EA, Houston GC, Hoffmann MB, Morland AB (2007) Pigmentation predicts the shift in the line of decussation in humans with albinism. Eur J Neurosci 25: 503-511. [Crossref]

25. Guillery RW, Hickey TL, Kaas JH, Felleman DJ, Debruyn EJ, et al. (1984) Abnorma central visual pathways in the brain of an albino green monkey (Cercopithecusaethiops) J Comp Neurol 226: 165-183. [Crossref]

26. Hoffmann MB, Tolhurst DJ, Moore AT, Morland AB(2003) Organization of the visual cortex in human albinism. J Neurosci 23: 8921-8930. [Crossref]

27. Stone J, Rowe MH, Campion JE (1978) Retinal abnormalities in the Siamese cat. $J$ Comp Neurol 180: 773-782.[Crossref]

28. Hellström A, Wiklund LM, Svensson E, Albertsson-Wikland K, Strömland K(1999) Optic nerve hypoplasia with isolated tortuosity of the retinal veins: A marker of endocrinopathy. Arch Ophthalmol 117: 880-884. [Crossref]

29. Jacobson L, Hellström A, Flodmark O (1997) Large cups in normal-sized optic discs a variant of optic nerve hypoplasia in children with periventricular leukomalacia. Arch Ophthalmol 115: 1263-1269. [Crossref]

30. Hellström A, Svensson E (1998) Optic disc size and retinal vessel characteristics in healthy children. Acta Ophthalmol Scand 76: 260-267. [Crossref]

31. Gundersen KG, Heijl A, Bengtsson B (1996) Sensitivity and specificity of structural optic disc parameters in chronic glaucoma. Acta Ophthalmol Scand 74: 120125. [Crossref]

Copyright: (C2016 Conley J. This is an open-access article distributed under the terms of the Creative Commons Attribution License, which permits unrestricted use, distribution, and reproduction in any medium, provided the original author and source are credited. 